\title{
Pleural Biphasic Mesothelioma
}

National Cancer Institute

\section{Source}

National Cancer Institute. Pleural Biphasic Mesothelioma. NCI Thesaurus. Code C45665.

Malignant mesothelioma that arises from the pleura. It is characterized by the presence of epithelioid and sarcomatoid components, with each component representing at least $10 \%$ of the tumor. 